\title{
ESTIMATING ABOVE GROUND BIOMASS OF PINUS ROXBHURGHII USING SLOPE BASED VEGETATION INDEX MODEL
}

\author{
A. M. Joshi ${ }^{1, *}$, S. Shahnawaz ${ }^{2}$, B. Ranjit ${ }^{3}$ \\ 1 Genesis Consult Pvt. Ltd, , Lalitpur, Nepal - joshi.atulman@ gmail.com \\ ${ }^{2}$ University of Salzburg, Salzhurg, Austria - Shahnawaz.Shahnawaz@sbg.ac.at \\ ${ }^{3}$ Land Management Training Center, Ministry of Land Management, Cooperatives and Poverty Alleviation, Dhulikhel, \\ Kavrepalanchok, Nepal - ranjit.bhuwan@gmail.com
}

Commission V, WG V/7 \& Commission IV, WG IV/6

KEY WORDS: Above Ground Biomass, Vegetation Index, NDVI, RATIO, TVI, CTVI, TTVI, Pinus roxbhurghii

\begin{abstract}
:
Pinus roxburghii is one of the important and most widely planted tree species in Nepal. Despite its large abundance and high economic values, limited studies on its AGB have been conducted in Nepal, especially using in situ non-destructive method. There are different methods to study the AGB. Regression equation based on the correlation between VI and AGB is cost effective method, and replicable in another sites of similar environment by just acquiring satellite images. Numerous methods have been developed to calculate VIs and each calculated VI shows different relation with AGB in different environments for same species. Therefore, there is a need to identify a most appropriate VI that has the highest correlation with AGB of $P$. roxburghii. The current study was carried out in Hattiban and Dollu community forests of Kathmandu district, using ResourceSat-2 imagery. In this study, Slope based VIs were used. Regression analysis between slope based VIs and AGB showed that relation between all VIs and AGB were significant. However, NDVI had the highest relation with AGB compared to others. Therefore, it was concluded that NDVI was the most appropriate VI to estimate AGB of $P$. roxburghii, and the regression equation with NDVI was used to estimate the AGB of $P$. roxburghii in the study area.
\end{abstract}

\section{INTRODUCTION}

Biomass is defined as the mass of living or dead organisms in a given area at a given time. It comprises of above ground biomass (AGB) and below ground biomass, but AGB is generally used to estimate the biomass because it accounts for the greatest fraction of total living biomass. AGB is defined as "the total amount of above ground living organic matter in trees expressed as oven-dry tons per unit area (tree, hectare, region, or country)" (FAO, 1997). There are different methods to study the AGB. The traditional destructive measurement method is expensive, time consuming, laborious and destroys forest (FAO, 2012). Ground based inventory using allometric equation is accurate, but it requires a large number of sample plots and also cannot measure the spatial distribution of AGB in large area (Anderson, 2007; Lu et al., 2004; Soenen et al., 2010). Hence, it is time consuming, labour intensive and costly. Integrating remote sensing data along with forest resource inventory (field data) is a cost effective method and provides a geo-statistical basis for estimating AGB of large area i.e. AGB of large area can be estimated by linking information derived from remotely sensed data to AGB values measured on the ground (Anderson, 2007; Zhu \& Liu, 2014; Brewer et al., 2012).

Remotely sensed data comprises information of different spectral bands. Combination of red and near infrared (NIR) spectral bands produce vegetation indices (VIs), which have relationship with AGB (Brewer et al., 2011; Bajracharya, 2008; Lu et al., 2004) and are commonly used to estimate AGB using a regression equation (Dong et al., 2003; Lu et al., 2004; Zheng et al., 2004; Tucker et al., 1985, Bajracharya, 2008). Spectral radiances from red and NIR bands have distinct interaction with plants. The energy from red band is strongly absorbed by the plant pigments for photosynthesis, while energy from NIR band is strongly scattered by the internal structure of the leaves. This strong contrast between the amount of reflected energy in red and NIR bands helps to develop vegetation indices (VIs). Using this, different types of VIs have been developed (Eastman, 1999).

Although, VIs have relationship with AGB, the strength of the relation depends upon several factors such as background surface condition, amount of standing green biomass, atmospheric condition and local environment (Anderson \& Hanson, 1992). As a result, different studies have reported different results. Sader et al. (1989) did not find NDVI as a reliable VI to estimate AGB. Sader et al. (1989) did not find difference in biomass in young tropical forest using NDVI and concluded that NDVI was not suitable for estimating AGB in uneven and mixed broadleaved forest. Similar result was reported by Hall et al. (1995). On the other hand, Anderson et al (1993) found a strong relation between NDVI and AGB in-semi arid rangelands. Likewise, Mundava et al. (2014) found that VIs have strong relation with AGB in open plain land that refers to areas with periodic flooding with mostly annual grasses, while relation did not exist in Spinifex grass dominated areas. Lu et al. (2004) found a positive relation between AGB and VI (principal component, component1) in Pedras of Brazil, but in Altamira and Bragantina, they found a negative relation. This variation was accounted for difference in biophysical environment of study area as the relationship depends upon plant species and their local environment (Mundava et al., 2014; Lu et al., 2004). Since the relation between VIs and AGB for a particular species differs from one VI to another, and from one place to another (different environment), one species shows higher relation on one VI, while other on another, depending upon the local

\footnotetext{
* Corresponding author
} 
environment. Hence, a need of identifying the best VI to quantify the AGB for a particular species at a particular site is highly felt. As such, the present study has focused to identify the most appropriate VI to estimate the AGB of Pinus roxburghii, a widely planted tree species with economic value. In this study, Slope based VI has been used as it is used to study the status and abundance of vegetation cover and AGB (Eastman, 1999). The current study was carried out in Hattiban and Dollu community forests of Kathmandu district, using ResourceSat-2 imagery.

\section{STUDY AREA AND MATERIALS}

\subsection{Study Area}

The study area is located at Hattiban and Dollu community forests in Dakshinkali Municipality of Kathmandu district. It is about $18 \mathrm{~km}$ south of Kathmandu city. It covers an area of 3.69 $\mathrm{km} 2$ (369 hectares), and extends between latitude of $27^{\circ} 36^{\prime} 43.142^{\prime \prime}$ and $27^{\circ} 38^{\prime} 37.309^{\prime \prime}$ North and longitude of $85^{\circ} 14^{\prime} 54.041^{\prime \prime}$ and $85^{\circ} 17^{\prime} 13.3358^{\prime \prime}$ East. The elevation of the study area ranges from $1505 \mathrm{~m}$ to $2037 \mathrm{~m}$. The study area falls in subtropical bio-climatic zones, with maximum temperature of about $35.6^{\circ} \mathrm{C}$ in April and minimum of up to $-3^{\circ} \mathrm{C}$ in January. The annual average humidity is $75 \%$ and the average rainfall is $1400 \mathrm{~mm}$ per annum. Most of the rainfall occurs in the months of June to August. The study area consists of different plant species that are not native to the area, and were planted during afforestation program. The southern aspect of the study area is dominated by $P$. roxburghii, while the northern aspect is mixed with broad leaved and $P$. roxburghii. Schima wallichi,
Castapnopsis indica, Rhododendron spp. are some of the plant species present in the area (DFO, 2014).

\subsection{Data Description}

Satellite imagery of $5 \mathrm{~m}$ resolution (ResourceSat-2, Scene ID: RS2-LISS4-24-Jan-2015-104-52, acquired on January 24, 2015) was obtained from India Space Research Organization. ResourceSat-2 is a "data continuity mission of ISRO (Indian Space Research Organization) with improved spectral bands of the IRSP6/ResourceSat-1" (ESA, 2016). Digital elevation model (DEM) of 1 arc-second (30 $\mathrm{m}$ resolution) (ID: SRTM1N27E085V3), of Shuttle Radar Topography Mission (SRTM) was used for orthorectification.

\section{METHODOLOGY}

\subsection{Sampling}

Based on equation proposed by Husch et al. (2003), a minimum of 34 sample plots was required at $95 \%$ Confidence interval (CI). Quadrant size of $10 * 10 \mathrm{~m}^{2}$ as proposed by Oosting (1942) was used for the sampling. Taking sample plots greater than $10 * 10 \mathrm{~m}^{2}$ was not possible in the study area as there were steep slopes. Within the sample plot, diameter at breast height (DBH) and height of $P$. roxburghii were taken because AGB calculation requires the data of $\mathrm{DBH}$ and height of the tree. Sample plots were laid only in areas where $P$. roxburghii is homogenously present.

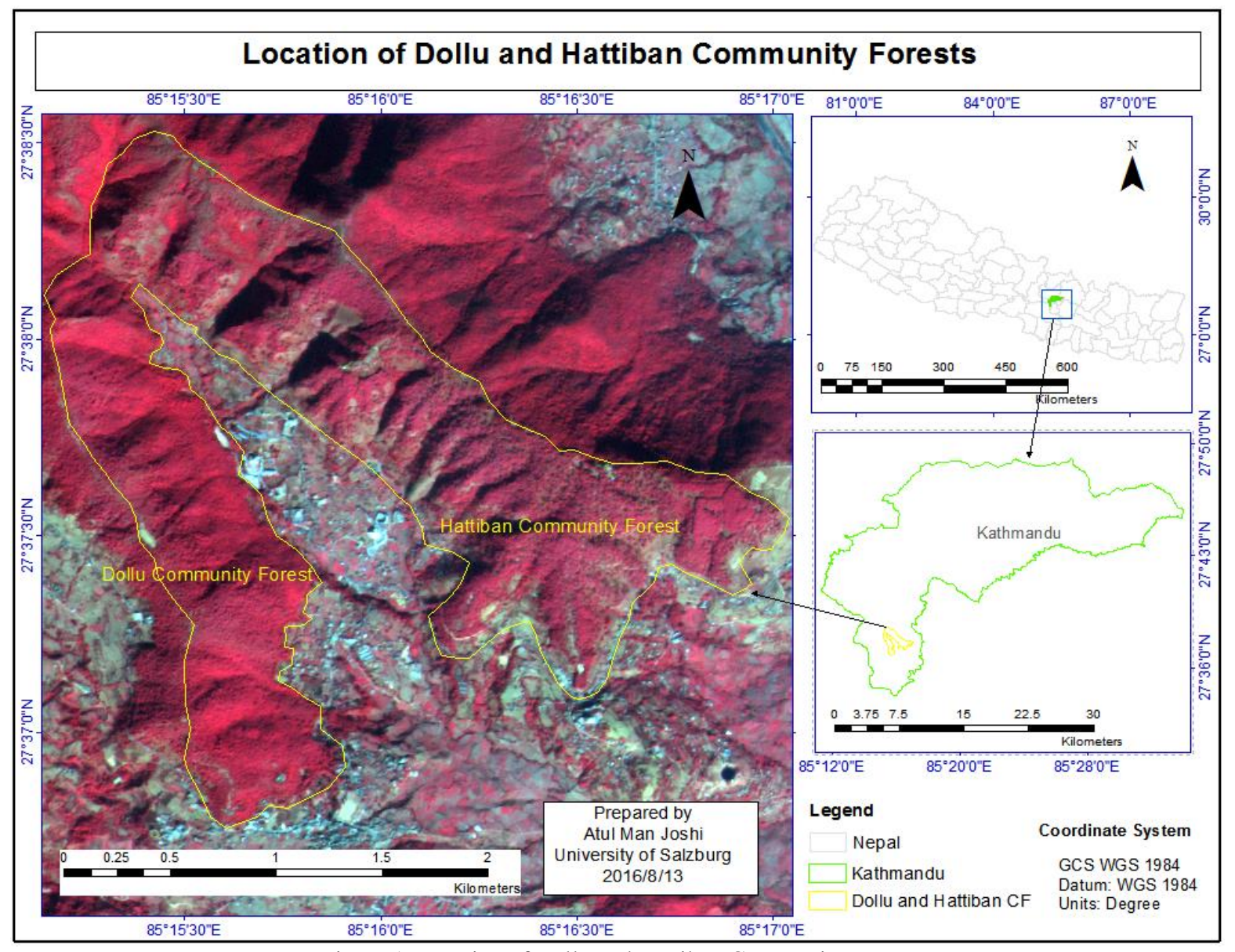

Figure 1. Location of Dallu and Hattiban Community Forest 


\subsection{Data Analysis}

The data collected in the field were analyzed to calculate AGB of $P$. roxburghii. AGB was calculated from the volumetric and structural dimension of the trees. DBH and height are the major parameters for measuring AGB (Pokhrel, 2015). AGB of $P$. roxburghii of sample plots was calculated using equation proposed by DFRS (2014).

AGB $=$ Stem biomass + Branch biomass + Foliage biomass

Stem biomass $=$ Volume* Density

$\ln (V)=a+b \ln (D)+c \ln (H)$

where $\ln (V)=$ Natural logarithm to the base 2.71828, $V=$ Stem volume, $D=D B H, H=$ Tree height, $a, b$ and $c$ are coefficients (Sharma \& Pukkala, 1990; DFRS, 2014)

Branch and foliage biomass were calculated using branch to stem biomass ratio and foliage to stem biomass ratio as proposed by MoFSC (1988).

\subsection{Image Processing}

\subsubsection{Image Orthorectification}

Ortho-rectification is the process of removing distortion due to terrain relief and off vertical imaging geometry. It creates an ortho-image that has features positioned as they would be in planimetric map. ResourceSat-2 image was ortho-rectified using Rational polynomial coefficient (RPC) supplied by image vendor, ground control points and DEM.

\subsubsection{Atmospheric Correction}

Atmospheric correction was done using COST model developed by Chavez (1996). The model uses cosine of sun zenith as an acceptable parameter for approximating the effects of absorption by atmospheric gases and Rayleigh scattering. The radiance is then converted to surface reflectance by correcting solar (includes corrections for sun elevation angle, amount of solar irradiance for the individual spectral bands and earth sun distance) and atmospheric effects.
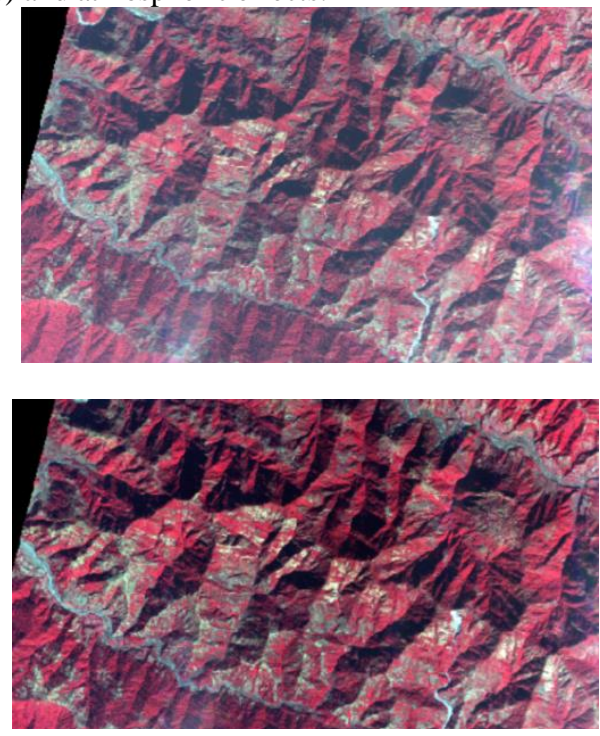

Figure 2. Image before (above) and after (below) atmospheric correction using COST Model

\subsubsection{Vegetation Indices (VIs)}

VIs are the combination of different spectral bands, usually red and NIR, of satellite data that produce a single image representing the amount of vegetation present. Low index value represents little healthy vegetation, while high value represents higher healthy vegetation. VIs are used to estimate AGB, monitor environmental changes and land degradation (Kogan, 1990; Kogan \& Liu, 1996; Tripathy et al. 1996). In this study slope-based VI was used as it is applied to study the status and abundance of vegetation cover and AGB. Slope based VI is the simple linear combination that uses the reflectance of red and NIR spectral bands and focuses on the contrast between the spectral response pattern in the red and NIR portion of electromagnetic spectrum. The term "Slope based was coined because any value of the index can be produced by a set of red and NIR reflectance values that form a line emanating from the origin of a bi-spectral plot"(Eastman, 1999). Following are the slope based VIs used in the study.

\subsubsection{Ratio Vegetation Index}

Ratio Vegetation Index (RATIO) was proposed by Rouse et al. (1974) to separate green vegetation from soil background. It is the ratio of NIR and Red bands (Equation 4).

$$
R A T I O=\frac{N I R}{R e d}
$$

The result clearly captures the contrast between the read and NIR bands vegetation pixel, with higher index values being produced by combination of low red (because of absorption by chlorophyll) and high NIR (as a result of leaf structure) reflectance. The index is susceptible to division by zero.

\subsubsection{Normalized Difference Vegetation Index}

Normalized Difference Vegetation Index (NDVI) was proposed by Rouse et al. (1974) to produce a VI that differentiates green vegetation from soil. It is the difference between NIR and red bands normalized by the sum of those bands (Equation 5).

$$
N D V I=\frac{N I R-R e d}{N I R+R e d}
$$

\subsubsection{Transformed Vegetation Index}

Transformed Vegetation Index (TVI), proposed by Deering et al. (1975), modifies NDVI by adding a constant of 0.50 to all its values and taking the square root of the results. The constant is used to remove the negative NDVI values, while the square root is used to transform NDVI histogram into a normal distribution (Equation 6).

$$
T V I=\sqrt{N D V I+0.5}
$$

\subsubsection{Corrected Transformed Vegetation Index}

Corrected Transformed Vegetation Index (CTVI) was proposed by Perry \& Lautenschlager (1984), which aims to correct the TVI. Adding a constant 0.50 to NDVI does not always remove negative values, therefore to remove the negative values, the 
$(\mathrm{NDVI}+0.5)$ is divided by its absolute value $\mathrm{ABS}(\mathrm{NDVI}+0.5)$ and the result is multiplied by the square root of the absolute value (Equation 7).

$$
C T V I=\frac{(N D V I+0.5)}{|(N D V I+0.5)|} \sqrt{|(N D V I+0.5)|}
$$

\subsubsection{Thiam's Transformed Vegetation Index}

Thiams (1997) found that resulting image from CTVI can be noisy due to over estimation of greenness, therefore he suggested using Thiams's Transformed Vegetation Index (TTVI) that ignores first term of CTVI equation and uses ABS(NDVI + 0.5) (Equation 8).

$$
T T V I=\sqrt{|N D V I+0.5|}
$$

\subsubsection{Image Classification}

Object based classification was used to classify image. It involves segmenting an image into objects, and uses both spectral and spatial pattern for classification. Apart from imageries, image derivatives like PCA, VI, ancillary data like DEM were also used for classification in object based classification. Multi-resolution segmentation and CART Classifier algorithm were used for classifying the image. Land Use Land Cover classes-Agriculture, Barren land, Built up, Forest and Water bodies - were present in the area. However, the current study focused on $P$. roxburghii only, therefore, Forest class was subdivided into $P$. roxbhurgii and Broad leaved classes, and all other remaining classes were grouped into other class. The accuracy of the classified land use land cover was $87.18 \%$.

\subsection{Statistical Analysis}

Correlation between VIs and AGB of $P$. roxburghii was calculated to show the relation between the two variables. Two variables are said to be correlated if change in one variable affects the other variable. If increase in one variable increases the other variable, then these variables are considered to have positive correlation. In contrast to this, if increase in one variable decreases the other variable or vice versa, then variables are considered to have negative correlation. The degree of relationship is represented by correlation coefficient (r) (Shrestha, 1996).

Regression analysis is used to show the relationship between dependent and independent variables, as well as predict or estimate the value of one variable (dependent) based on the value of another variable (independent) (Shrestha, 1996). Multiple $\mathrm{R}$ square explains the extent of variability in the dependent variable explained by all independent variable. It assumes all independent variable affects the dependent variable. On the other hand, the adjusted $\mathrm{R}$ square explains the variation explained by independent variables that only affect the dependent variable. For a successful relation, the adjusted $\mathrm{R}$ square should be at least 0.5 (Mundava, et al., 2014). Regression equation (model) was developed and used to predict the AGB (dependent variable) of the study area covered by $P$. roxburghii based on the independent variable, VIs.

\section{RESULTS AND DISCUSSION}

\subsection{Landuse Land Cover}

Land Use Land Cover (LULC) of the study area showed that $P$. roxburghii occupied an area of $2.12 \mathrm{~km}^{2}$ (57.45\% of total area), broadleaved species occupied $0.63 \mathrm{~km}^{2}$ (17.07\% of total area) and other class occupied $0.94 \mathrm{~km}^{2}$ (25.47\% of total area). The accuracy of the classified land use land cover showed that the overall accuracy of the land use land cover was $87.18 \%$, with Kappa index of 0.7613.

\subsection{Statistics of Field Data}

Analysis of field data showed that diameter at breast height (DBH) of $P$. roxburghii ranged from $11 \mathrm{~cm}$ to $65 \mathrm{~cm}$, with mean $\mathrm{DBH}$ of $30.44 \mathrm{~cm}$. The height of $P$. roxburghii ranged from $10 \mathrm{~m}$ to $33 \mathrm{~m}$, with mean height of $22.68 \mathrm{~m}$, while the volume of $P$. roxburghii ranged from $0.05 \mathrm{~m}^{3}$ to $5.21 \mathrm{~m}^{3}$, with mean volume of $0.9849 \mathrm{~m} 3$. AGB in the sample plots ranged from 2,284.02 to $13,259.91 \mathrm{~kg}$ per plot. The average AGB of the sample plots was $6,482 \mathrm{~kg}$ per plot.

\subsection{Correlation Analysis}

Correlation analysis between slope based VIs and AGB showed significant correlation with correlation coefficient (r) above 0.7 . The correlation coefficient in all of the VIs were almost same having relatively higher correlation $(r=0.734)$ in NDVI.

\begin{tabular}{lc}
\hline Slope based VIs & Correlation coefficient \\
\hline RATIO and AGB & 0.731 \\
NDVI and AGB & 0.734 \\
TVI and AGB & 0.733 \\
CTVI and AGB & 0.733 \\
TTVI and AGB & 0.733 \\
\hline
\end{tabular}

Table 1. Correlation between sloped based VIs and AGB

\subsection{Regression Analysis}

Regression analysis between slope based VIs and AGB (Table 2) showed that multiple R-square $\left(\mathrm{r}^{2}\right)$ values were almost similar and ranged from 0.5348 to 0.5388 . Similarly, Adjusted $\mathrm{R}$ square (adjusted $\mathrm{r}^{2}$ ) values ranged from 0.5207 to 0.5248 . Mundava et al. (2014) noted that the adjusted $\mathrm{r}^{2}$ value should be at least 0.5 for the regression equation to be significant and to predict the dependent variable. Hence, the adjusted $r^{2}$ value ( 0.5207 to 0.5248$)$ showed that the relation between all VIs and AGB were significant.

However, NDVI was relatively more significant $\left(\mathrm{r}=0.734, \mathrm{r}^{2}=\right.$ 0.5388 and adjusted $\mathrm{r}^{2}=0.5248$ ) for $P$. roxburghii in the study area. Similar results were also obtained by different researchers. Jin et al. (2014) found a significant relation $\left(r^{2}=0.60\right)$ between NDVI and AGB in grassland of Northern China. Zhu \& Liu (2014) found a strong relation $\left(r^{2}=0.63\right)$ between NDVI and AGB in the senescing period, when vegetation attains maximum leaves and greenness, compared to other seasons. Edirishnghee et al. (2011) also found a significant relation between NDVI and AGB in pasture land. Liu et al. (2006) compared the relation between different VIs and biomass in Oasis ecosystem, and found that NDVI had higher relation $\left(r=0.862, r^{2}=0.743\right)$ with biomass. Dong et al. (2003) also concluded that NDVI and biomass has a statistically significant relation and the regression 
model can be used to estimate the biomass across spatial, temporal and ecological scales for relatively long time scales.

On the other hand, Heiskanen (2006) found Ratio $(r=0.90)$ to have better relation that NDVI $(\mathrm{r}=0.81)$ with AGB in mountain birch forest. Lu et al. (2004) also found similar results in Bragatina, where Ratio $(r=0.530)$ showed higher relation with
AGB, compared to NDVI (0.459). Das \& Singh (2012) studied the relation between VI and AGB in forests of Maharashtra, and also found Ratio to have higher relation $\left(\mathrm{r}^{2}=0.785\right)$ compared to NDVI $\left(\mathrm{r}^{2}=0.75\right)$. Anderson \& Hanson (1992) studied the relation between VIs (Ratio and NDVI) and AGB in different months for two consecutive years and found that the Ratio had better relation with AGB than NDVI. In the month of July,

\begin{tabular}{llllll}
\hline \multirow{2}{*}{\begin{tabular}{c} 
Regression equation \\
\multicolumn{1}{c}{ and Statistics }
\end{tabular}} & Ratio VI & NDVI & TVI & CTVI & TTVI \\
\cline { 2 - 6 } & $\begin{array}{l}\text { AGB }=-5251 \\
+3091 * \text { Ratio }\end{array}$ & $\begin{array}{l}\text { AGB }=-4501+ \\
16199 * \text { NDVI }\end{array}$ & $\begin{array}{l}\text { AGB }=-26789 \\
+30325 * \text { TVI }\end{array}$ & $\begin{array}{l}\text { AGB }=-26789 \\
+30325 * \text { CTVI }\end{array}$ & $\begin{array}{l}\text { AGB }=-26789+ \\
30325 * \text { TTVI }\end{array}$ \\
Equation & 0.5348 & 0.5388 & 0.5385 & 0.5385 & 0.5385 \\
Multiple R-squared & 0.5207 & 0.5248 & 0.5245 & 0.5245 & 0.5245 \\
Adjusted R-squared & 37.93 & 38.55 & 38.51 & 38.51 & 38.51 \\
F-Statistics on 1 and 33 & 0.000000604 & 0.000000522 & 0.000000527 & 0.000000527 & 0.000000527 \\
P value & 6.159 & 6.209 & 6.205 & 6.205 & 6.205 \\
\hline
\end{tabular}

Table 2. Statistical summary of regression analysis between slope based VIs and AGB
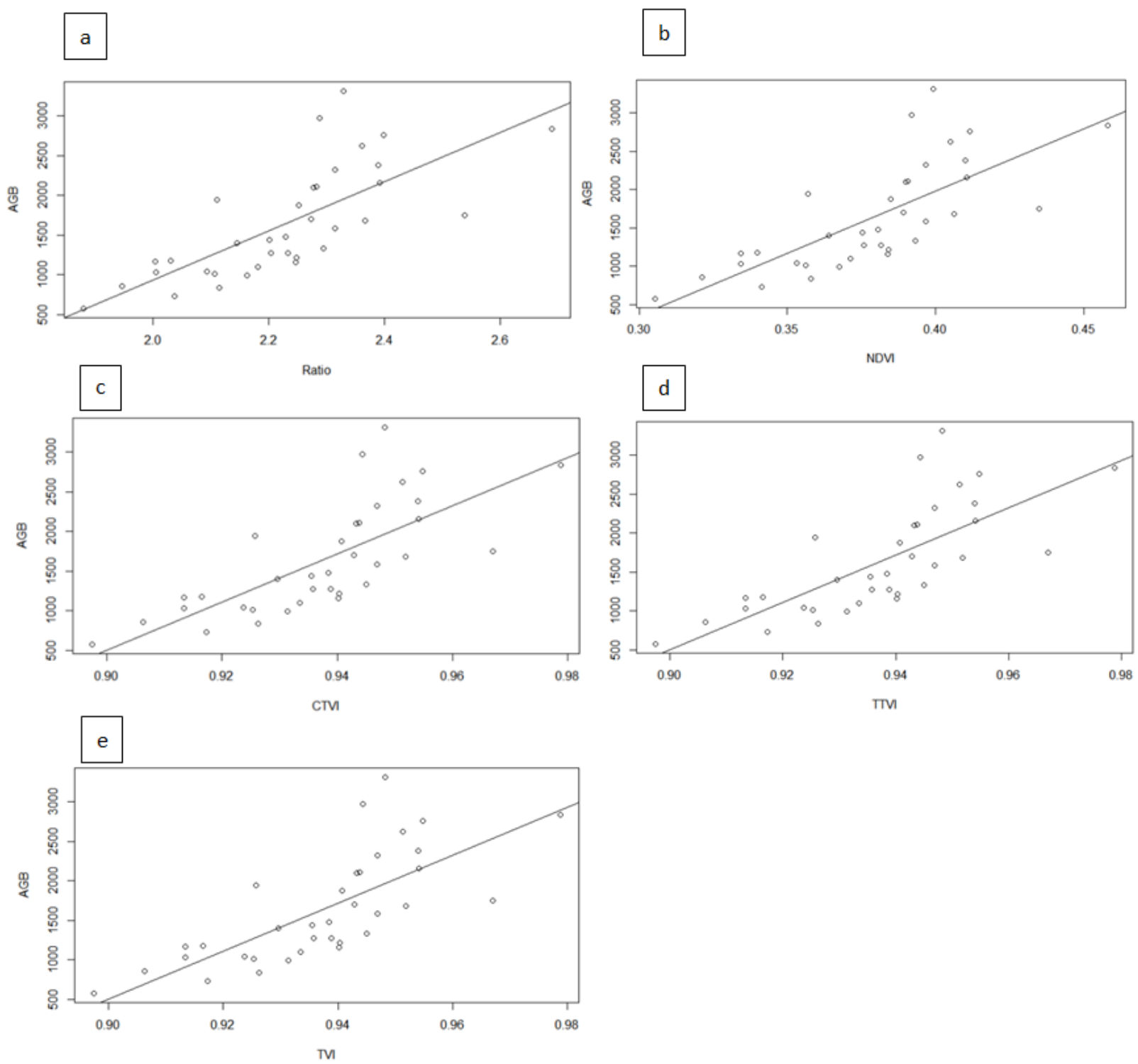

Figure 3. Regression analysis between slope based VIs and AGB - (a) between Ratio and AGB, (b) between NDVI and AGB, (c) between CTVI and AGB, (d) between TTVI and AGB, (e) between TVI and AGB 


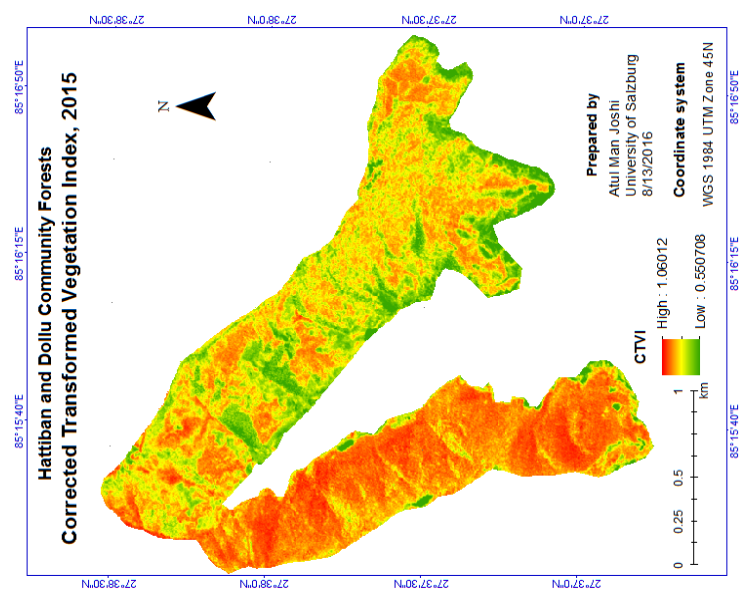


Ratio had the highest relation with AGB $\left(r^{2}=0.44\right)$, while the relation was insignificant in the month of October. NDVI also had similar results. NDVI had the highest relation with AGB $\left(\mathrm{r}^{2}\right.$ $=0.36)$ in the month of June, while the relation was insignificant in the month of October. In July, $\mathrm{r}^{2}$ for NDVI was 0.29. Mundava et al. (2014) compared the relation between NDVI and SAVI with AGB in different sites of Brazil, and found that in open plains, NDVI and SAVI showed same relation with AGB $\left(r^{2}=0.6\right)$. Similar result was found by them in bunchgrass also. But in Spinifex dominated areas, SAVI showed no relation with AGB $\left(r^{2}=0\right)$, while NDVI had very low relation with $\mathrm{AGB}\left(\mathrm{r}^{2}=0.1\right)$.

The variation in relation between VIs and AGB could be attributed to the variation in biophysical environments of the study area because the strength of the relation between VIs and AGB depends on various factors, including plant species and their environment (Anderson \& Hanson, 1992; Mundava et al., 2014 and Lu et al., 2004). As such, one species shows higher relation on one VI, while other on another, depending upon the local environment.

\subsection{Estimating AGB}

Since NDVI had the highest relation $\left(r=0.734, r^{2}=0.5388\right.$ and adjusted $r^{2}=0.5248$ ) with AGB compared to other VIs, NDVI based regression equation was used to estimate the overall AGB of $P$. roxburghii in the study area. Based on the above regression equation, the total AGB of $P$. roxburghii in the study area was estimated to be $133,577,495.44 \mathrm{~kg}$. The estimated AGB was cross validated with observed AGB from field using RMSE equation. The calculation resulted a RMSE of $41.49 \%$.

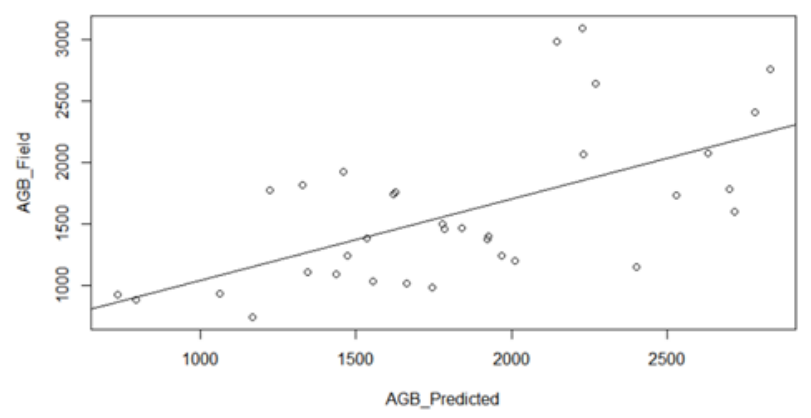

Figure 5. Relation between Observed and Predicted AGB

\section{CONCLUSION AND RECOMMENDATION}

Statistical analysis showed NDVI had the highest relation with AGB $\left(r=0.734\right.$, multiple $r^{2}=0.5388$, adjusted $\left.r^{2}=0.5248\right)$. Therefore, it was concluded that NDVI was the most appropriate VI to estimate $\mathrm{AGB}$ of $P$. roxburghii, and the regression equation with NDVI was used to estimate the AGB of $P$. roxburghii in the study area. Based on the regression equation, it was found that the AGB of $P$. roxburghii in the study area was $133,577,495.44 \mathrm{~kg}$. Cross validation of the estimated AGB with observed AGB from field showed RMSE of $41.49 \%$.

\section{REFERENCES}

Anderson, G. L., \& Hanson, J. D. (1992). Evaluating HandHeld Radiometer Derived Vegetation Indices for Estimating Above Ground Biomass. Geocarto International, 1, 71-78.
Anderson, G. L., Hanson, J. D., \& Haas, R. H. (1993). Evaluating Landsat Thematic Mapper Dervied Vegetation Indices for Estimating Above Ground Biomass on Semi Arid Rangeland. Remote Sensing of Environment, 45, 165-175.

Anderson, R. S. (2007). Lidar Based Estimates of Biomass, Woody Productivity and Land cover in the Chequamegon National Forest, Wisconsin. M.Sc Thesis, University of Minnesota, USA.

Bajracharya, S. (2008). Community Carbon Forestry: Remote Sensing of Forest Carbon and Forest Degradation in Nepal. M.Sc Thesis, ITC, Netherlands.

Brewer, C. K., Monty, J., Johnson, A., Evans, D., \& Fish, H. (2012). Forest Carbon Monitoring: A Review of Selected Remote Sensing and Carbon Measurement Tools for REDD. U.S. Department of Agriculture, Forest Service, Remote Sensing Applications Center.

Chavez, P. S. (1996). Image Based Atmospheric CorrectionsRevisted and Improved. Photogrammetric Engineering and Remote Sensing, 62(9), 1025-1036.

Das, S., \& Singh, T. P. (2012). Correlation Analysis between Biomass and Spectral Vegetation Indices of Forest Ecosystem. International Journal of Engineering and Research and Technology, 1(5).

Deering, D. W., Rouse, J. W., Haas, R. H., \& Schell, J. A. (1975). Measuring Forage Production of Grazing Units from Landsat MSS Data. 10th Internal Symposium on Remote Sensing of Environment, (pp. 1169-1178).

DFO. (2014). Samudahik Bann Anugaman ra Barsik Pragati Pratibedan (in Nepali). Kathmandu, Nepal: Ministry of Forest, GON.

DFRS. (2014). Churia Forests of Nepal. Kathmandu, Nepal: Department of Forest Research and Survey, Ministry of Forests and Soil Conservation, GON.

Dong, J., Kaufmann, R. K., Myeni, R. B., Tucker, C. J., Kauppi, P. E., Buermann, W., . . . Liski, J. (2003). Remote Sensing Estimates of Boreal and Temperate Forest Woody Biomass: Carbon Pools, Sources and Sinks. Remote Sensing of Environment, 84, 393-410.

Eastman, J. (1999). IDRISI 32, Guide to GIS and Image Processing. MA, USA: Clark University.

Edirisnghe, A., Hill, M. J., Donald, G. E., \& Hyer, M. (2011). Quantitative Mapping of Pasture Biomass using Satellite Imagery. International Journal of Remote Sensing, 32(10), 2699-2724.

FAO. (1997). Estimating Biomass and Biomass Change of Tropical Forests: a Primer. Retrieved 5 18, 2016, from http://www.fao.org/docrep/w4095e/w4095e04.htm

FAO. (2012). Guidelines on Destructive Measurement for Forest Biomass Estimation. UN-REDD Viet Nam Programme. Retrieved 4 26, 2016, from http://vietnamredd.org/Upload/CMS/Content/SWG.MRV/Biomass\%20guideli nes/Guidelines_on_destructive_measurement_EN(Ver1).doc. 
Hall, F. G., Shimabukuro, Y. E., \& Huemmrich, K. F. (1995). Remote Sensing of Forest Biophysical Structure using Mixture Decompositon and Geometric Refelectance Models. Ecological Society of America, 5, 993-1013.

Heiskanen, J. (2006). Estimating Aboveground Tree Biomass and Leaf Area Index in a Mountain Birch Forest using ASTER Satellite Data. International Journal of Remote Sensing, 27(6), $1135-1158$

Husch, B., Beers, T. W., \& Kershaw, J. A. (2003). Forest Mensuration (4th ed.). Hoboken, NJ, USA: John Wiley and Sons.

Jin, Y., Yang, X., Qiu, J., Li, J., Gao, T., Wu, Q., . . Xu, B. (2014). Remote Sensing Based Biomass Estimation and Its Spatio Temporal Variations in Temperate Grassland, Northern China. Remote Sensing, 6, 1496-1513.

Kogan, F. N. (1990). Remote Sensing of Weather Impacts on Vegetation in Nonhomogenous Areas. International Journal of Remote Sensing, 11(8), 1405-1419.

Kogan, F. N., \& Liu, W. T. (1996). Monitoring Regional Drought using the Vegetation Condition Index. International Journal of Remote Sensing, 17(14), 2761-2782.

Liu, W., Gao, W., Gao, Z., \& Wang, X. (2006). Correlation Analysis between the Biomass of Oasis Ecosystem and the Vegetation Index at Fukang. Remote Sensing and Modelling of Ecosystemn for Sustainability.

Lu, D., Mausel, P., Brondizio, E., \& Moran , E. (2004). Relationships Between Forest Stand Parameters and Landsat TM Spectral Response in the Brazilain Amazon Basin. Forest Ecology and Management, 198, 149-167.

Mundava, C., Helmholz, P., Schut, A., Corner, R., McAtee, B., \& Lamb, D. W. (2014). Evaluation of Vegetation Indices for Rangeland Biomass Estimation in the Kimberely Area of Western Australia. ISPRS Annals of the Photogrammetry, Remote Sensing and Spatial Information Sciences, 2(7), 47-53.

Perry, C., \& Lautenschlager, L. F. (1984). Functional Equivalence of Spectral Vegetation Indices. Remote Sensing and the Environment, 14, 169-182.

Pokhrel, S. (2015). Assessment of Above Ground Biomass and Fire Risk Zonation in Selected Forest Areas of LudhiKhola Watershed, Gorkha District, Nepal. M.Sc Thesis, University of Salzburg, Austria.

Rouse, J. W., Haas, R. H., Schell, J. A., \& Deering, D. W. (1974). Monitoring the Vernal Advancement and Retrogradation. NASA.

Sader, S. A., Waide, R. B., Lawrence, W. T., \& Joyce, A. T. (1989). Tropical Forest Biomass and Successional Age Class Relationships to a Vegetation Index derived from Landsat TM Data. Remote Sensing Environment, 28, 143-156.

Sharma , E. R., \& Pukkala, T. (1990). Volume Equations and Biomass Prediction of Forest Trees of Nepal. Kathmandu, Nepal: Forest Survey and Statistics Division.

Shrestha, S. (1996). An Introduction to Statistics. Kathmandu, Nepal: Ratna Pustak Bhandar.
Soenen, S. A., Peddle, D. R., Hall, R. J., Coburn, C. A., \& Hall, F. G. (2010). Estimating AboveGround Forest Biomass from Canopy Reflectance Model Inversion in Mountainous Terrain. Remote Sensing of Environment, 1325-1337.

Thiam, A. K. (1997). Geographic Information Systems and Remote Sensing Methods for Assessing and Monitoring Land Degradation in the Sahel: The Case of Southern Mauritania. Clark University.

Tripathy, G. K., Ghosh, T. K., \& Shah, S. D. (1996). Monitoring of Desertification Process in Karnataka State of India using Multi-Temporal Remote Sensing and Ancillary Information using GIS. International Journal of Remote Sensing, 17(12), 2243-2257.

Tucker, C. J., Vanpraet, C. L., Sharman, J., \& Ittersum, V. (1985). Satellite Remote Sensing of Total Herbaceous Biomass Production in the Senegalese Sahel. Remote Sensing of Environment, 17, 233-249.

Zheng, D., Rademacher, J., Chen, J., Crow, T., Bresee, M., Moine, J. L., \& Ryu, S. R. (2004). Estimating Above Ground Biomass using Landsat 7 ETM+ Data Across a Managed Landscape in Northern Wisconsin, USA. Remote Sensing of Environment, 93, 402-411.

Zhu, X., \& Liu, D. (2014). Improving Forest Above Ground Biomass Estimation using Seasonal Landsat NDVI Time-Series. ISPRS Journal of Photogrammetry and Remote Sensing, 1-10 